Review

\title{
Scaling up action for mental health in the Eastern Mediterranean Region: an overview
}

\author{
R. Gater ${ }^{1,2}$ and K. Saeed ${ }^{3}$
}

\section{The case for action}

One of the most pressing challenges to health systems globally, and in the World Health Organization (WHO) Eastern Mediterranean Region in particular, is that of effectively reducing the prevalence of mental disorders and the related disability and mortality.

Mental disorders are common and disabling. At any given time, about 1 person in every 10 is suffering from a mental disorder, and about 1 in 4 families has a member with a mental disorder (1). Rates of mental disorder are even greater where there are complex emergencies, such as are being faced by many countries in the Eastern Mediterranean Region. Globally, mental, neurological and substance-use disorders account for $22.9 \%$ of non-fatal disease burden (measured as years lived with disability) and $7.4 \%$ of the global burden of disease (measured as disability adjusted life years, a metric which encompasses years lived with disability as well as early death) (2).

Rates of suicide have increased by $60 \%$ over the past 45 years (3). Globally, 800000 people die by suicide each year, making it the tenth leading cause of death, and one of the 3 leading causes of death among people aged 15-44 years (4). Suicide is expected to account for more than $2 \%$ of the global burden of disease by 2020 (5).

The costs of mental disorders are already huge, and are expected to grow year-by-year. In 2010, the global costs of mental disorders were estimated at
US\$ 2.5 trillion (6). Over the next 20 years the cumulative global impact of mental disorders in terms of lost economic output will amount to US\$ 16 trillion. It is estimated that the cost of mental disorders in high-income countries, in terms of expenditures incurred and loss of productivity, equates to about $4 \%$ of gross national product (7), and it is predicted that the costs of mental disorders will more than double by 2030, affecting low- and middle-income countries as well as high-income countries.

Effective pharmacological and psychosocial treatments are available for depression, schizophrenia, epilepsy and alcohol and substance abuse, and these treatments can be successfully applied in low-income countries $(1,8)$. Nevertheless, the vast majority of people with a mental disorder do not receive treatment. The treatment gap between people who require care but do not receive treatment has been estimated to be more than $90 \%$ in the Eastern Mediterranean Region (9). The reason for this unacceptable gap is that mental disorders and services for those affected have been neglected in many countries worldwide (2). Until recently, mental health has not featured on the political agenda. Mental health policies and legislation have been either absent or outdated, and pay scant regard to the human rights of people with mental disorders.

Inadequate resources have been devoted to mental health: countries in the Eastern Mediterranean Region typically spend $2 \%$ of their health budget on mental health (10), which compares with the $5-10 \%$ required to match contemporary comprehensive health care systems. The median spend of US\$ 0.15 per person on mental health is well short of the US\$3-4 needed for a selective package of costeffective mental health interventions in low-income countries and up to US\$ 7-9 in middle-income countries (11). Furthermore, centralized and institutionalized care consumes a disproportionate amount of mental health expenditure. Evidence-based action can ensure that the limited resources available to mental health care are used cost-effectively.

The high prevalence, considerable disability and growing costs of mental disorders, taken together with the huge treatment gap despite the availability of cost-effective treatments, form a compelling case to reassess provision for mental health care. The WHO has taken up this challenge with the Comprehensive Mental Health Action Plan 2013-2020, which was adopted at the 66th World Health Assembly (12). This action plan sets out a new vision and goal for mental health: "A world in which mental health is valued, promoted and protected, mental disorders are prevented and persons affected by these disorders are able to exercise the full range of human rights and to access high quality, culturallyappropriate health and social care in a timely way to promote recovery, all in order to attain the highest possible level of health and participate fully in society 
and at work free from stigmatization and discrimination."

This is to be articulated through 4 objectives and 6 measurable global targets to be achieved by 2020 . The 4 objectives are:

- to strengthen effective leadership and governance for mental health;

- to provide comprehensive, integrated and responsive mental health and social care services in community-based settings;

- to implement strategies for promotion and prevention in mental health;

- to strengthen information systems, evidence and research for mental health.

The Eastern Mediterranean regional framework for implementation of the Comprehensive Mental Health Action Plan 2013-2020 operationalizes these 4 objectives, and translates them into concrete measurable activities with a set of intermediate indicators that can be used to monitor progress towards the targets for 2020. This theme issue on mental health contains papers on the components of the framework that concisely review the best available evidence and practices and identify the "best buys" for the Eastern Mediterranean Region to address priority mental health needs. These are reinforced with a set of resources and WHO tools to support countries planning and implementing national mental health action plans. Within the countries of the Region, there are examples of outstanding models of mental health provision that have been developed in local areas, some of which are referenced in the papers published in this issue.

\section{Situation analysis in countries of the Region (13)}

All 22 countries in the Eastern Mediterranean Region have submitted data in response to the questionnaire for the forthcoming Mental health atlas 2014, which collects a set of core mental health indicators to monitor progress in relation to the targets in the Comprehensive Mental Health Action Plan 2013-2020. Preliminary analysis of the Atlas suggests that some countries have started to address policy development and legislation, but there remain significant shortfalls in many areas, as detailed below.

- Mental health policy and legislation: Most countries report that they have a mental health policy (82\%) and mental health legislation (77\%), but only one-third are fully compliant with international human rights instruments. Mental health legislation in $23 \%$ of countries was enacted more than 10 years ago.

- Service user empowerment and participation: Around 23\% of countries have a formal published policy on the participation of service users and carers. In most countries service-user involvement is absent during the formulation and implementation of mental health policies, plans, legislation and services.

- Investment in mental health: The government is the main provider of funds for care and treatment of severe mental disorders in $77 \%$ of countries. However, few countries were able to submit data to the Mental health atlas project on annual mental health expenditure by the government. This may indicate that budgets are not specifically allocated and ring-fenced for mental health.

- Human resources: The size of the mental health workforce varies greatly across the Region. Among the countries that submitted relevant data, about a quarter have more than 20 mental health staff per 100000 population, two-thirds have 5-19 staff per 100000 population, and 1 country has less than 1 staff member per 100000 population.

- Integration of mental health in primary health care: The extent of mental health training for primary care doc- tors and nurses varies greatly between countries. A median of $29 \%$ of primary care doctors and $5 \%$ of primary care nurses have received at least 2 days of mental health training in the past 2 years.

- Mental hospitals: In about one-third of countries, more than $85 \%$ of the mental health workforce is deployed to work in mental hospitals. Across the Region, a median of $74 \%$ of admissions were involuntary. Over onethird of reporting countries indicated that one-third or more of mental hospital patients had stays greater than 5 years.

- Promotion and prevention: Around $27 \%$ of countries have no mental health promotion and prevention programmes, and a further $27 \%$ have only $1-3$ such programmes.

- Suicide prevention: Only $18 \%$ of countries have a national suicide prevention strategy, and only $23 \%$ were able to report data on numbers of suicides. The annual rate of suicide ranges between 4 and 44 per 1000000 population.

- Information systems: Almost half the countries have not published a specific mental health information report in the past 2 years although $14 \%$ have published reports on both the public and private sector. The difficulty in providing information for the Mental Health Atlas 2014 questionnaire, particularly on expenditure, professionals working in different settings, service coverage and suicide, suggests that many countries are managing with very rudimentary information systems.

\section{Effective leadership and governance for mental health}

Planning and implementation for the transformation of mental health care will need robust and committed leadership and governance from 
national governments (ministries of health) working with other public sector entities and other partners, in both the private sector and civil society, to implement the plan. Without effective leadership and governance, any attempt for national reform of mental health care will falter. This requires a dedicated mental health unit/department within the health ministry, and countries may consider appointing an individual director of the mental health unit/department responsible for overseeing the development and governance of policy, plans and legislation.

Government commitment to improving mental health can also establish national values for mental health care by adopting and promulgating the cross-cutting principles of the Comprehensive Mental Health Action Plan 2013-2020 in the governance framework. Having a wide representation in governance structures, including service users and families as well as a range of other stakeholders, is a means of ensuring that the principles of equitable universal health coverage; respect for human rights; culturally-sensitive evidence-based practice; addressing the whole life course; a coordinated and comprehensive multisectoral approach; and the empowerment and involvement of people with mental disorders and psychosocial disabilities are woven into the way that leadership and governance procedures are established and managed.

The keyleadership and governance responsibilities are in the development and oversight of the implementation of mental health policies and plans, mental health legislation and finances. These form the supporting framework in which mental health services will be delivered. It is crucial that they complement and support each other; for example, mental health laws should codify the fundamental principles, values, aims and objectives of mental health policies and plans, and budgets need to be allocated to achieve the targets of the national mental health plan.

\section{Mental health policy and strategic plan}

A mental health policy expresses the national vision for mental health and articulates the key objectives and areas for action to achieve that vision. In the associated action plan these are translated into concrete actions, time frames, targets and indicators for measuring progress and outcomes. Some countries have a dedicated mental health policy and plan, while in others mental health is incorporated in general health, disability, or other related policies and plans. The important elements that need to be included in a mental health policy and plan are summarized in a separate paper in this theme issue (14).

\section{Key strategic interventions for mental health policy and strategic plan}

- Establish/update a multisectoral national policy/strategic action plan for mental health in line with international/regional human rights instruments.

- Establish a common governance structure, as appropriate to the national context, to facilitate and monitor implementation of the multisectoral national policy/strategic action plan.

\section{Mental health legislation}

Modern mental health legislation is important to establish and enforce the basic requirements for human rights protection, quality of care and service development. National legislation must also conform to legal obligations agreed in international human rights treaties such as the United Nations Convention on the rights of persons with disabilities (15). Mental health legislation may stand alone as a single, consolidated mental health law or it may be fully or partially integrated into other relevant legislation. In a separate paper in this theme issue, Funk and Drew delineate the aspects of mental health law that should be clearly articulated in the legislation (16).

\section{Key strategic interventions for mental health legislation}

- Review legislation related to mental health in line with international human rights covenants/instruments.

- Establish a mechanism to independently monitor the implementation of updated legislation.

\section{Investing in mental health}

Mental health financing is not only about costs but should also be informed by the cross-cutting principles of the Comprehensive Mental Health Action Plan 2013-2020. It is important to provide equitable access to services and a system of financial contributions that is fair and avoids the risk of potential catastrophic financial consequences of health care for individuals and their families. To meet the goal of this action plan, it is essential that governments take responsibility for ensuring that a national budget adequate to meet the mental health needs is secured, and that appropriate and fair financing arrangements are put in place to use the available resources in a cost-effective and equitable way.

Alongside assessing resource needs and coverage targets, ministries need to prioritize adequate budgetary allocations to support the mental health policy/plans. These steps are linked to the 3 dimensions which are considered when moving towards universal health coverage (Figure 1). The adoption of community-based care and the integration of mental health into primary health care and other service delivery 
platforms will expand the population that is equitably covered. Evidence regarding mental health interventions that can be delivered more cost-effectively in the community than in a hospital-based service is provided by Chisholm in a paper elsewhere in this theme issue (18).

\section{Key strategic interventions for investing in mental health}

- Include defined priority mental conditions in the basic health delivery package of the government and so$\mathrm{cial} / \mathrm{private}$ insurance reimbursement schemes.

- Increase and prioritize budgetary allocations for addressing the agreed upon service targets and priorities, including providing transitional/bridge funding.

\section{Reorganizing mental health services: from institutional to community- based models of care}

The main thrust of the global action plan is transformation of the provision of mental health care so that it becomes accessible to all and makes efficient use of the resources available to provide effective mental health care in a way that is equitable while fully respecting the human rights of people with mental disorders and their carers. At the heart of mental health care is the health and social care service along with the promotion of mental health and well-being and the prevention of mental disorders. Together these form the interface of mental health care with individuals, families and communities. These complementary approaches are the means towards achieving the goal of the Comprehensive Mental Health Action Plan 2013-2020 "to promote mental well-being, prevent mental disorders, provide care, enhance recovery, promote human rights and reduce the mortality, morbidity and

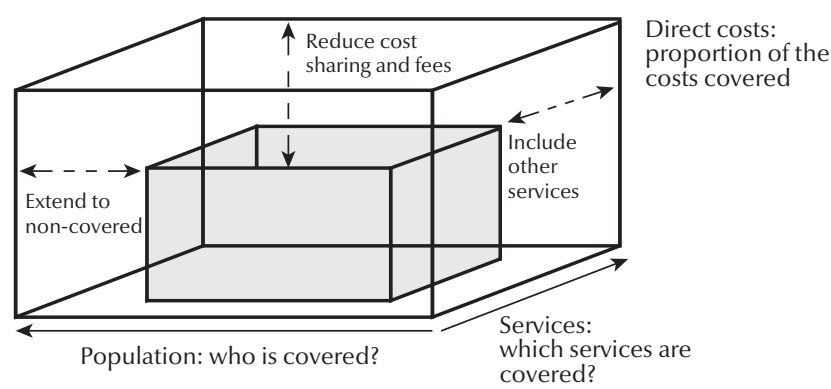

Figure 1 Universal health care cube (17) disability for persons with mental disorders".

The WHO has proposed the service organization pyramid for an optimal mix of services for mental health (Figure 2). This model incorporates the recovery paradigm that people with mental disorders are central to their own recovery and they can manage their mental health problems themselves, supported by family, friends and community institutions. At successively higher levels of the pyramid the mental health needs of the individual require more-intensive professional assistance with correspondingly higher costs of care.
There is a strong consensus, supported by evidence reviewed by Saraceno et al., that a balanced approach to secondary mental health services incorporating both communityandhospital services offers the best model for a modern mental health service (20). The components of this balanced approach are detailed here.

- Integration of mental health into primary care and other priority healthcare programmes, such as Making Pregnancy Safer, the Expanded Programme on Immunization, and integrated child care programmes: This wholly accords with the aims of the WHO Mental Health Gap Action Programme (mhGAP)

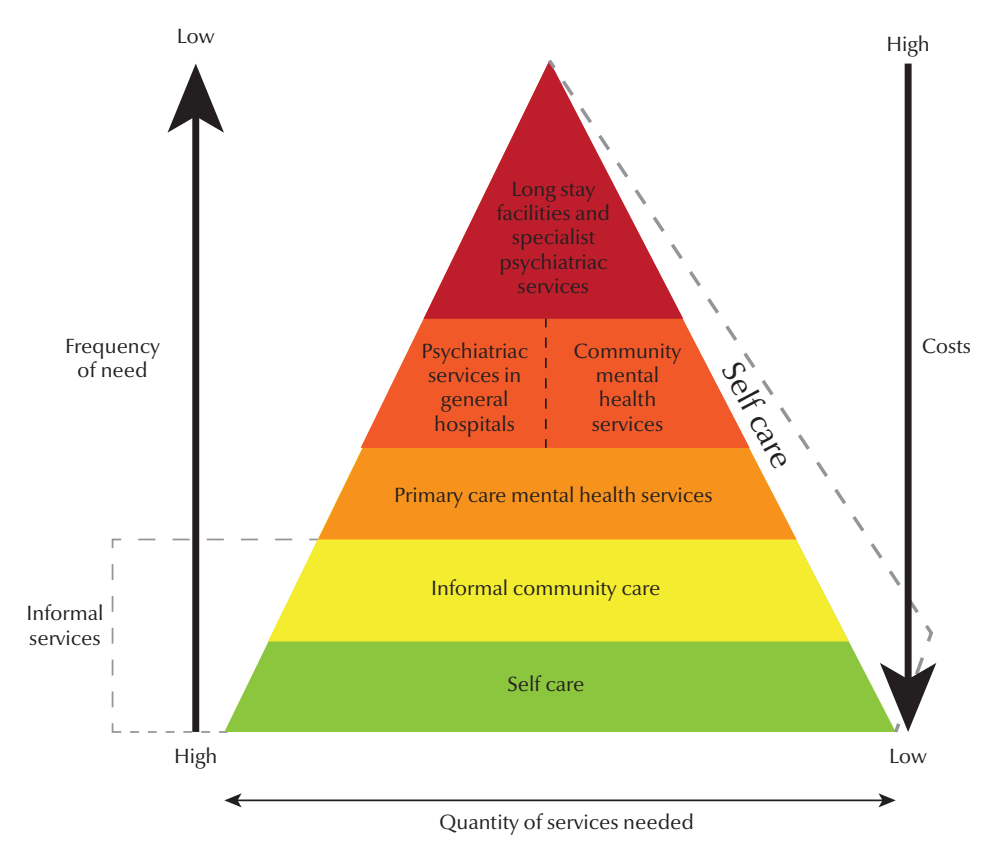

Figure 2 WHO service organization pyramid for an optimal mix of services for mental health (19) 
to scale up care for mental, neurological and substance misuse disorders by delivering pharmacological and psychosocial interventions in nonspecialized health care settings.

- Scaling up community-based mental health services such as multidisciplinary community outreach teams for defined catchment populations, provision of supported residential facilities within community settings, supported employment, and family support: Community-based care offers a cost-effective alternative that can support recovery and self-care, and patients report greater satisfaction. Many countries have developed successful pilot sites of community services, but few have scaled them up to cover the whole population to provide equitable access for all.

- Establishing mental health services in general hospitals for outpatient and acute inpatient care: Compared with the psychiatric hospital, this is more accessible to the majority of people, is less stigmatizing, and provides the ideal setting for coordinated treatment of comorbid physical and mental disorders.

- Scaling down and refocusing psychiatric hospitals: Centralized, institutionalized care in psychiatric hospitals is expensive, inefficient and inaccessible. Psychiatric hospital-based care consumes a disproportionate amount of mental health expenditure, and many inpatients become long-stay patients and have poor clinical and social outcomes. Rehabilitation programmes are often inadequate, and psychiatric hospitals are associated with human rights violations. Current long-stay patients will need careful assessment and planned rehabilitation to help them regain the skills to live outside the hospital supported by community mental health services. More-immediate action can, however, be taken to progressively reduce the number of long-stay beds in mental hospitals through restricting new admissions and providing community/general hospital-based alternatives to admission to the psychiatric long-stay beds.

- Human resources to deliver integrated community-based care: Evidence on the development, deployment and retention of human resources for mental health services has been reviewed by Ivbijaro et al. (21). By engaging primary and general health care staff in mental health care, the coverage, availability, accessibility and acceptability of such care can be greatly expanded. Most of the recurrent mental health budget is spent on salaries. It is therefore crucial to recruit, develop and retain a multidisciplinary workforce with the mix of skills, involving tasksharing/shifting, training and supervision, to deliver community-based care. Where most mental health staff are based in psychiatric hospitals there will be a need for some to reorient and retrain to work in the community. There is a risk that those who remain in the hospital will become demoralized and one way to address this is through enhancing the expertise of the psychiatric hospital staff and transforming the hospitals into tertiary referral centres of excellence for specialized inpatient care or for patients with care needs that cannot be fully met by the mental health units based in general hospitals.

The optimal balance of mental health services for each country varies according to population needs and available resources: areas with low levels of resources may need to focus on improving mental health care in primary health care with specialist back-up, while countries with more available resources can supplement primary health care with more-direct care from specialist mental health services in the community and in hospital.

\section{Key strategic interventions for reorganizing mental health services}

- Establish mental health services in general hospitals for outpatient and short-stay inpatient care.
- Integrate delivery of evidence-based interventions for priority mental conditions in primary health care, supported by referral systems.

- Integrate delivery of interventions for mental health conditions into priority health programmes.

- Enable people with mental health conditions and their families through self-help and community-based interventions.

- Downsize the existing long-stay mental hospitals and ensure protection of the rights of people with mental health conditions.

\section{Promotion and primary prevention: priorities for implementation}

Mental health promotion and prevention interventions can improve the mental health of the population by reducing risk factors and addressing social determinants for mental disorders, enhancing protective factors for good mental and physical health, and contributing to lasting positive effects on a range of social and economic outcomes. Selected promotion and prevention programmes for reducing the increasing burden of mental disorders and improving the overall health and well-being of the population should be integrated into national health and development strategies.

Barry et al. review the extensive global evidence demonstrating that preventive interventions are cost-effective, feasible and affordable (22). This evidence has been used to identify the following "best buys" for the Eastern Mediterranean Region.

- Infant and maternal health and combined nutritional and parenting skills: Integrating mental health promotion and prevention into routine prenatal and postnatal care services improves child development and parenting 
skills, reduces behavioural problems and improves maternal health and social functioning. This generates economic savings for government and benefits to society. Benefits are especially evident for the most vulnerable families, including those living in poverty or war-torn areas, babies who are undernourished and mothers with depression.

- Life skills for schoolchildren: Social and emotional learning interventions in schools produce sustained benefits in children's social and emotional functioning and their academic performance. Furthermore, they are cost-saving in terms of their positive impact on crime and health outcomes. Targeted interventions for children at higher risk (for example children living in a complex emergency) enhance coping skills, resilience and cognitive skills and are effective in preventing anxiety and depression.

- Suicide prevention: There is growing evidence that interventions such as responsible media reporting; restricting access to means; training of health personnel for early recognition and management of priority mental, neurological, and substance use disorders; and school-based skills training and social support for at-risk students are effective in high-income countries. However, further evaluation and modification is needed in the context of the countries of the Eastern Mediterranean Region. Preliminary measures towards suicide prevention that should be established in all countries of the Region include setting up systems to capture information about the rates of suicides/suicide attempts, methods employed and demographic characteristics along with the decriminalization of suicide.

- Promotion of mental health literacy: The evidence for the effectiveness of mental health literacy programmes such as mass media promotion, dedicated websites, school education programmes and mental health first aid training is mainly from high-income countries. Therefore, the decision to implement these interventions has to be taken based on the individual context of each country. Internet interventions have been shown to be at least as effective as face-to-face interventions at reducing stigma, and it could be relatively inexpensive to adapt existing websites for Eastern Mediterranean Region countries.

\section{Key strategic interventions for the promotion of mental health and primary prevention of mental disorders}

- Integrate recognition and management of maternal depression and parenting skills training into maternal and child health programmes.

- Integrate life skills education, using a whole school approach.

- Reduce access to means of suicide.

- Employ evidence-based methods to improve mental health literacy and reduce stigma.

\section{Mental health and psychosocial support in humanitarian emergencies}

Complex emergency situations pose particular challenges, causing mental health problems that can go on to become persistent and disabling. The disruption of an emergency can also undermine the organization and provision of necessary care for people with an established mental disorder who are being treated in hospital or the community. A disproportionately high number of countries in the Region have had, or are continuing to deal with, complex emergencies. Van Ommeren et al. review the evidence for 4 strategic interventions aimed at helping countries prepare for and minimize the damaging effects of complex emergencies on mental health (23).

\section{Key strategic interventions for humanitarian emergencies}

- Embed mental health and psychosocial support in national emergency preparedness and ensure the strengthening of mental health systems as part of recovery.

- Train emergency responders to provide psychological first aid.

- Strengthen the capacity of health professionals in the recognition and management of priority mental conditions during emergencies.

- Implement evidence-informed interventions for psychosocial assistance to vulnerable groups.

\section{Mental health surveillance and information systems}

The core foundation of planning and development is evidence; this includes both evidence about the local needs and services and research evidence about innovations. Gater, Chisholm and Dowrick describe how information about local needs and service delivery is crucial to monitoring and planning improvements in service provision (24). The paucity of reliable information in many countries in the Region has impaired the ability of planners to develop services that are responsive and meet the needs of the population. The goal of the Comprehensive Mental Health Action Plan 2013-2020 requires relevant, high quality, mental health and service indicators to be collected and reported (Figure 3). Some of these indicators will be incorporated into routine national data collection and others may need to be supplemented by periodic surveys. The WHO is developing the use of recent advances in information technology to explore how the internet and data warehousing techniques can be best harnessed to support data collection, intersectoral collaboration and data sharing and dissemination. 


\section{Key strategic interventions for surveillance and information systems}

- Integrate the core indicators within the national health information systems; a proposed list of core mental health indicators is included in the Eastern Mediterranean regional framework for implementation of the comprehensive mental health action plan (25).

- Routinely record and report suicides at national level.

\section{Mental health research: priorities and use to inform policies \& services}

The second key source of evidence is mental health research, which has been reviewed by Regan et al. (26). Mental health research is critical to guiding rational policy development, strategic programme planning and the reorganization of mental health services. Prioritizing mental health research, particularly implementation research, can generate enormous returns in terms of reducing disability and preventing premature death. To an extent, the findings from mental health research can be generalized and applied in different countries but this does not necessarily take account of the culture, services, economics and other circumstances in countries of the Eastern Mediterranean Region. It is therefore important that countries identify their own research priorities, mobilize resources and enhance their human and infrastructural research capacity so that they have relevant research findings to guide the development of policies and service delivery models.

\section{Key strategic interventions for mental health research}

- Enhance the national capacity to undertake prioritized research.
- Engage stakeholders in research planning, implementation and dissemination.

\section{Comprehensive systems approach of the Regional framework for implementing the Mental Health Action Plan 2013-2020}

A comprehensive systems approach is the means by which sustainable change can be achieved. The mental health and social care services and the promotion of mental health and well-being and prevention of mental disorders are at the centre of mental health care delivery, but they can only perform their role successfully if properly supported by all the other components (Figure 4). They are directly influenced by resources and information (middle ring in Figure 4). They need to be manned by a workforce that is appropriately skilled and structured for the task. They need to be adequately financed, and during a period of change they require transitional funding so that the old and new services can be balanced and run in parallel while the new services are established. They need information and research to monitor how successfully they meet their objectives and to inform further planning, development and innovation. The mental health service needs essential medicines to be continuously available both in hospital and community settings. Mental health care delivery operates within the overarching framework set in the national policy and plan, and within the legal framework of mental health laws (outer ring in Figure 4). All these

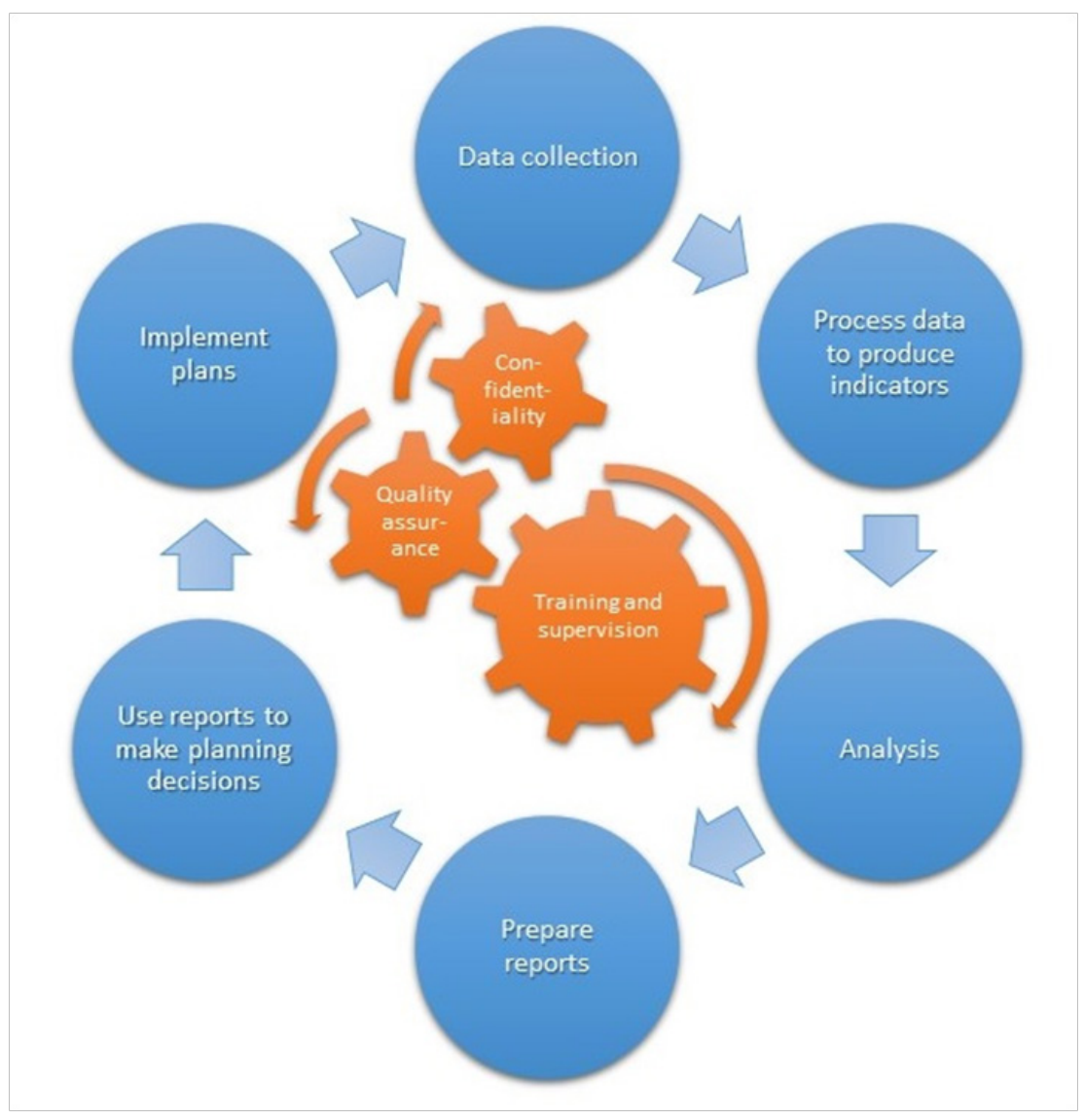

Figure 3 Information loop 


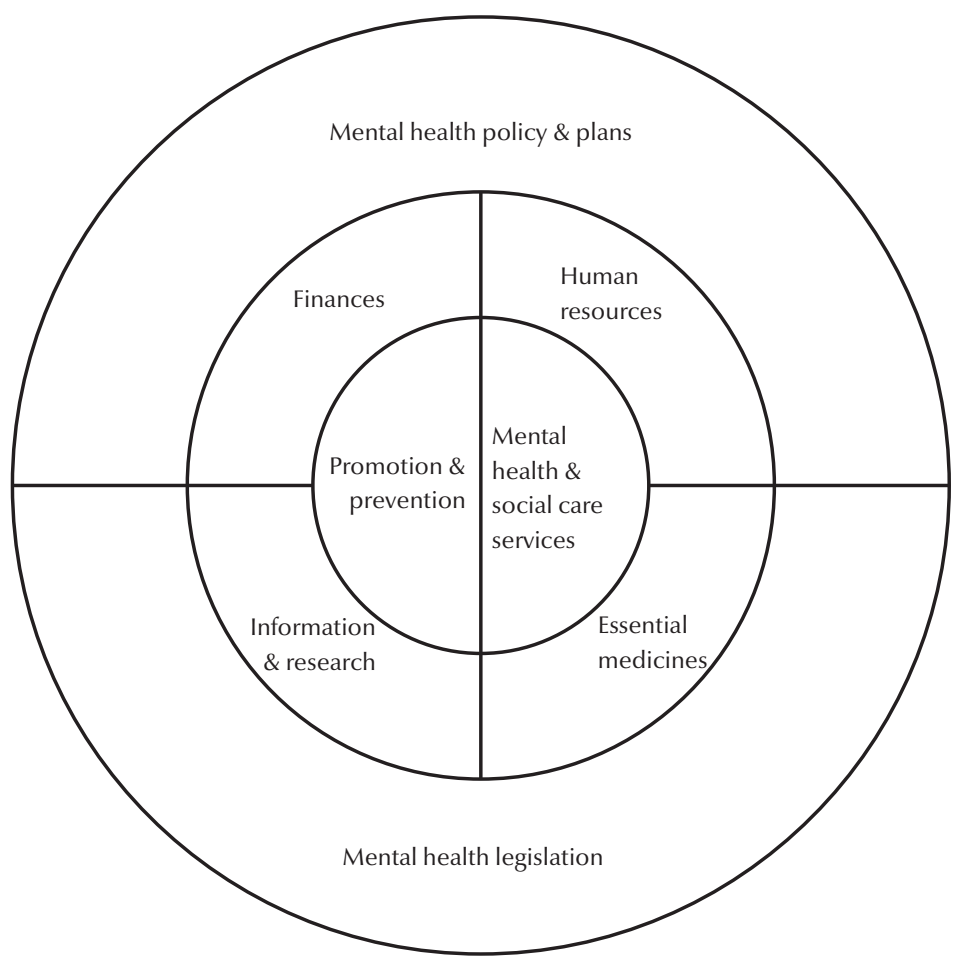

Figure 4 Synergy of the components of the mental health service component parts must be actively involved in meeting the mental health challenge and orchestrated so that they work harmoniously together. For example, resources must be made available at the right time in the process of service development, research must be relevant to inform future planning and development, and legislation must support the developing model of community care.

The key strategic interventions identified have been brought together in the Eastern Mediterranean regional framework for implementation of the Comprehensive Mental Health Action Plan 2013-2020 (25). In the framework, the implementation of the strategic interventions is supported by a set of WHO tools and proposed indicators that will be used biennially until 2020 to monitor progress towards the targets of the Action Plan.

\section{References}

1. The world health report 2001 - Mental health: new understanding, new hope. Geneva: World Health Organization; 2001 (http://www.who.int/whr/2001/en/, accessed 18 April 2015).

2. Whiteford HA, Degenhardt L, Rehm J, Baxter AJ, Ferrari AJ, Erskine $\mathrm{HE}$, et al. Global burden of disease attributable to mental and substance use disorders: findings from the Global Burden of Disease Study 2010. Lancet. 2013 Nov 9;382(9904):1575-86. PMID:23993280.

3. Scott A, Guo,B. HEN synthesis report; for which strategies of suicide prevention is there evidence of effectiveness? Copenhagen: World Health Organization Regional Office for Europe: 2012 (http://www.euro.who.int/_data/assets/ pdf_file/0003/168843/HEN-Suicide-Prevention-synthesisreport.pdf, accessed 18 April 2015).

4. Suicide data. Geneva: World Health Organization; 2012 (http://www.who.int/mental_health/prevention/suicide/ suicideprevent/en/, accessed 18 April 2015).

5. Public health action for the prevention of suicide: a framework. Geneva: World Health Organization; 2012 (http://apps. who.int/iris/bitstream/10665/75166/1/9789241503570_eng. pdf, accessed 18 April 2015).

6. Bloom DE et al. The global economic burden of non-communicable diseases. Geneva: World Economic Forum; 2011 (http://www.weforum.org/reports/global-economic-burden-non-communicable-diseases, accessed 18 April 2015).

7. Investing in mental health - evidence for action. Geneva: World Health Organization; 2013 (http://apps.who.int/iris/ bitstream/10665/87232/1/9789241564618_eng.pdf, accessed 18 April 2015).

8. Patel V, Araya R, Chatterjee S, Chisholm D, Cohen A, De Silva M, et al. Treatment and prevention of mental disorders in low-income and middle-income countries. Lancet. 2007 Sep 15;370(9591):991-1005. PMID:17804058.

9. Regional strategy on mental health and substance abuse. Geneva: World Health Organization; 2012 (WHO-EM/ MNH/191/E) (http://applications.emro.who.int/dsaf/EMROPUB_2012_EN_1067.pdf?ua=1, accessed 18 April 2015).

10. Mental health atlas 2011: resources for mental health in the Eastern Mediterranean region. Cairo: World Health Organization Regional Office for the Eastern Mediterranean; 2013 (EMRO Technical Publications Series 41) (http://applications. emro.who.int/dsaf/emropub_2013_1578.pdf, accessed 19 April 2015).

11. Hyman S, Chisholm D, Kessler R, Patel V, Whiteford H. Mental disorders. In: Jamison DT, Breman JG, Measham AR, Alleyne G, Claeson M, Evans DB, et al., eds. Disease control priorities related to mental, neurological, developmental and substance abuse disorders. Washington (DC): World Bank; 2006.

12. Mental health action plan 2013-2020. Geneva: World Health Organization; 2013 (http://www.who.int/mental_health/ publications/action_plan/en/, accessed 15 April 2015).

13. Gater R, Chew A. Saeed K. Situational analysis: preliminary review of the Mental Health Atlas 2014. East Mediterr Health J. 2015; 21(7):467-76

14. Funk MK, Drew NJ. Mental health policy and strategic plan. East Mediterr Health J. 2015; 21(7):522-6.

15. Convention on the rights of persons with disabilities. New York: United Nations; 2006 (http://www.un.org/disabilities/ convention/conventionfull.shtml. accessed 15 April 2015).

16. Funk MK. Drew NJ. Mental health legislation. East Mediterr Health J. 2015; 21(7):527-30. 
17. World health report 2010. Health systems financing: the path to universal coverage. Geneva: World Health Organization; 2010.

18. Chisholm D. Investing in mental health. East Mediterr Health J. 2015; 21(7):531-4.

19. Improving health systems and services for mental health. Geneva: World Health Organization; 2009.

20. Saraceno B, Gater R, Rahman A, Saeed K, Eaton J, Ivbijaro G, et al. Reorganization of mental health services: from institutional to community-based models of care. East Mediterr Health J. 2015; 21(7): 477-85.

21. Ivbijaro G, Patel V, Chisholm D, Goldberg D, Khoja TAM, Edwards T. Informing mental health policies and services in the EMR: cost-effective deployment of human resources to deliver integrated community-based care. East Mediterr Health J. 2015; 21(7):486-92.
22. Barry MM, Clarke AM, Peterson I. Promotion of mental health and prevention of mental disorders: priorities for implementation. East Mediterr Health J. 2015; 21(7):503-11.

23. Van Ommeren M, Hanna F, Weissbecker I, Ventevogel P. Mental health and psychosocial support in humanitarian emergencies. East Mediterr Health J. 2015; 21(7):498-502.

24. Gater R, Chisholm D, Dowrick C. Mental health surveillance and information systems. East Mediterr Health J. 2015; 21(7):512-6.

25. Eastern Mediterranean Regional Framework for Implementation of the Comprehensive Mental Health Action Plan . Cairo: World Health Organization Regional Office for the Eastern Mediterranean; 2015.

26. Regan M, Gater R, Rahman A, Patel V. Mental health research: developing priorities and promoting its utilization to inform policies and services. East Mediterr Health J. 2015; 21(7):517-21.

\section{Resources}

The following resources were useful in preparing the framework and are recommended as useful resources in implementing the framework.

\section{WHO}

- Mental health action plan 2013-2020. Geneva: World Health Organization; 2013 (http://www.who.int/mental_health/publications/ action_plan/en/, accessed 15 April 2015).

- Regional strategy on mental health and substance abuse. Cairo: World Health Organization; 2012 (WHO-EM/MNH/191/E) (http:// applications.emro.who.int/dsaf/EMROPUB_2012_EN_1067.pdf?ua=1, accessed 18 April 2015).

- WHO MiNDbank: more inclusiveness needed in disability and development. Geneva: World Health Organization; 2015 (http://www. mindbank.info/, accessed 19 April 2015).

- WHO mental health gap action programme (mhGAP) (intervention guide for mental, neurological and substance use disorders in nonspecialized health settings). Geneva: World Health Organization; 2011 (http://www.who.int/mental_health/mhgap/en/, accessed 19 April 2015).

- Mental Health Atlas 2011. Geneva: World Health Organization; 2011 (http://www.who.int/mental_health/publications/mental_ health_atlas_2011/en/, accessed 19 April 2015).

- Mental health atlas 2011: resources for mental health in the Eastern Mediterranean region. Cairo: World Health Organization Regional Office for the Eastern Mediterranean; 2013 (EMRO Technical Publications Series 41) (http://applications.emro.who.int/dsaf/emropub_2013_1578.pdf, accessed 19 April 2015).

- Investing in mental health: evidence for action. Geneva: World Health Organization; 2013 (http://apps.who.int/iris/bitstre am/10665/87232/1/9789241564618_eng.pdf, accessed 19 April 2015).

- The WHO mental health policy and service guidance package. Geneva: World Health Organization; 2009 (http://www.who.int/mental_health/policy/essentialpackage1/en/, accessed 19 April 2015).

\section{Lancet series on global mental health 2007 and 2011}

- Global mental health 2007. Lancet. 3 September 2007 (http://www.thelancet.com/series/global-mental-health, accessed 6 May 2015).

- Global mental health 2011. Lancet. 18 October 2011 (http://www.thelancet.com/series/global-mental-health-2011, accessed 6May 2015).

\section{PLoS series on grand challenges}

- Patel V, Belkin GS, Chockalingam A, Cooper J, Saxena S, Unitzer J. Grand challenges: integrating mental health services into priority health care platforms. PLoS Med. May 2013;10(5):e1001448 (http://www.ncbi.nlm.nih.gov/pmc/articles/PMC3666874/, accessed 19 April 2015).

- Collins PY, Insel TR, Chockalingam A, Daar A, Maddox YT. Grand challenges in global mental health: integration in research, policy and practice. PLoS Med. 2013;10(5):e1001434 (http://www.ncbinlm.nih.gov/pmc/articles/PMC3640093/, accessed 19 April 2015).

- Kaaya S, Eustache E, Lapidos-Salaiz I, Musisi S, Psaros C, Wissow L. Grand challenges: improving HIV treatment outcomes by integrating interventions for co-morbid mental illness. PLoS Med. 2013;10(5):e1001447 (http://www.ncbi.nlm.nih.gov/pubmed/23700389, accessed 19 April 2015).

- Rahman A, Surkan PJ, Claudina E. Cayetano CE, Rwagatare P, Dickson KE. Grand challenges: integrating maternal mental health into maternal and child health programmes. PLoS Med. 2013;10(5):e1001442. (http://www.plosmedicine.org/article/info:doi/10.1371/journal. pmed.1001442, accessed 19 April 2015). 


\section{WHO-Gulbenkian Foundation}

- World Health Organization and Calouste Gulbenkian Foundation. Integrating the response to mental disorders and other chronic diseases in health care systems. Geneva: World Health Organization; 2014 (http://www.who.int/mental_health/publications/gulbenkian_paper_integrating_mental_disorders/en/, accessed 19 April 2015).

- World Health Organization and Calouste Gulbenkian Foundation. Innovation in deinstitutionalisation: a WHO expert survey. Geneva: World Health Organization; 2014 (http://www.who.int/mental_health/publications/gulbenkian_innovation_in_deinstitutionalization/en/, accessed 19 April 2015).

- World Health Organization and Calouste Gulbenkian Foundation. Social determinants of mental health. Geneva: World Health Organization; 2014 (http://www.who.int/mental_health/publications/gulbenkian_paper_social_determinants_of_mental_health/en/, accessed 19 April 2015).

\section{WISH Report}

- Transforming lives, enhancing communities: innovations in mental health. Report of the Mental Health Working Group, World Innovation Summit for Health, Doha, 10-11 December 2013 (http://www.wish-qatar.org/app/media/381, accessed 19 April 2015).

\section{Mental health and psychosocial support in emergencies}

- United Nations Children's Fund and World Health Organization. Integrating early childhood development (ECD) activities into nutritional programmes in emergencies: why, what and how. Geneva: World Health Organization; 2012 (http://www.who.int/mental_health/publications/emergencies_why_what_how/en/, accessed 19 April 2015).

- Building back better: sustainable mental health care after emergencies. Geneva: World Health Organization; 2013 (http://www.who.int/ mental_health/emergencies/building_back_better/en/,accessed 19 April 2015).

- Psychological first aid_facilitators manual for orienting field workers. Geneva: World Health Organization; 2013 (http://apps.who.int/ iris/bitstream/10665/102380/1/9789241548618_eng.pdf, accessed 19 April 2015).

- World Health Organization and United Nations High Commission for Refugees. Assessing mental health and psychosocial needs and resources: toolkit for humanitarian settings. Geneva: World Health Organization; 2012 (http://www.who.int/mental_health/resources/ toolkit_mh_emergencies/en/, accessed 19 April 2015).

- WHO, War Trauma Foundation and World Vision International. Psychological first aid: guide for field workers. Geneva: World Health Organization; 2011 (http://www.who.int/mental_health/publications/guide_field_workers/en/, accessed 19 April 2015).

- Minimum standards in health action: Essential health services. In: The sphere handbook: humanitarian charter and minimum standards in humanitarian response. Geneva: The Sphere Project; 2011 (http://www.sphereproject.org/handbook/, accessed 6 May 2015).

- IASC Reference Group for Mental Health and Psychosocial Support in Emergency Settings. Mental health and psychosocial support in humanitarian emergencies: what should humanitarian health actors know? Geneva: World Health Organization; 2010 (http://www.who. int/mental_health/publications/what_should_humanitarian_health_actors_know/en/, accessed 19 April 2015).

- IASC guidelines on mental health and psychosocial support in emergency settings. Geneva: Inter-Agency Standing Committee; 2007 (http://whqlibdoc.who.int/iasc/2007/9781424334445_eng.pdf, accessed 19 April 2015).

- Mental health and psychosocial well-being among children in severe food shortage situations. Geneva: World Health Organization; 2006 (http://www.who.int/nutrition/publications/emergencies/WHO_MSD_MER_06.1/en/, accessed 19 April 2015

\section{Integrating mental health in primary health care}

- Thornicroft G, Tansella M. The balanced care model for global mental health. Psychol Med. 2013 Apr;43(4):849-63. PMID: 22785067.

- Eaton J, McCay L, Semrau M, Chatterjee S, Baingana F, Araya R, et al. Scale up of services for mental health in low-income and middle-income countries. Lancet. 2011 Oct 29;378(9802):1592-603. PMID: 22008429.

- Integrating mental health into primary care: a global perspective. Geneva: World Health Organization and World Organization of Family Doctors; 2008. (http://www.who.int/mental_health/policy/services/mentalhealthintoprimarycare/en/, accessed 19 April 2015).

\section{Suicide and suicide prevention}

- Preventing suicide: a global imperative. Geneva: World Health Organization; 2014 (http://www.who.int/mental_health/suicide-prevention/world_report_2014/en/, accessed 19 April 2015).

- Preventing suicide: a manual for case registration of suicide and attempted suicide. Cairo: World Health Organization Regional Office for the Eastern Mediterranean; 2014 (http://applications.emro.who.int/dsaf/EMRPUB_2014_EN_1688.pdf?ua=1, accessed 19 April 2015).

- Public health action for the prevention of suicide: a framework. Geneva: World Health Organization; 2012 (http://apps.who.int/iris/bitstr eam/10665/75166/1/9789241503570_eng.pdf, accessed 19 April 2015).

- Suicide data. Geneva: World Health Organization; 2005 (http://www.who.int/mental_health/prevention/suicide/suicideprevent/en/, accessed 19 April 2015). 


\section{Prevention and promotion}

- Barry MM, Clarke AM, Jenkins R, Patel V. A systematic review of the effectiveness of mental health promotion interventions for young people in low and middle income countries:. BMC Public Health. 2013 Sep; 13:835. PMID: 24025155.

- Kieling C, Baker-Henningham H, Belfer M, Conti G, Ertem M, Omigbodun O, Rohde L, Srinath S, Ulkuer, N, Rahman A. (2011) Global child and adolescence mental health: evidence for action. Lancet. 378(9801):1515-1525.

- Knapp M, McDaid D, Parsonage M, eds. Mental health promotion and prevention: the economic case. London: Personal Social Services Research Unit, London School of Economics and Political Science; 2011 (http://www.lse.ac.uk/businessAndConsultancy/LSEEnterprise/ pdf/PSSRUfeb2011.pdf, accessed 19 April 2015).

- Petersen I, Bhana A, Flisher AJ, Swartz L, Richter L, eds. promoting mental health in scarce-resource contexts: emerging evidence and practice. Cape Town: Human Sciences Research Council Press; 2010 (https://open.uct.ac.za/bitstream/handle/11427/2412/Promoting_Mental_Health.pdf?sequence=1, accessed 19 April 2015).

- O'Connell MA, Boat T, Warner K. preventing mental, emotional and behavioral disorders among young people: progress and possibilities. Washington (DC): National Academies Press; 2009 (https://www.ncbi.nlm.nih.gov/books/NBK32775/, accessed 19 April 2015).

- Barry MM, Jenkins R. Implementing mental health promotion. Edinburgh: Churchill Livingstone Elsevier; 2007.

- World Health Organization, Department of Mental Health and Substance Abuse in collaboration with the Victorian Health Promotion Foundation and University of Melbourne. Promoting mental health: concepts, emerging evidence, practice. Summary report. Geneva: World Health Organization; 2005 (http://www.who.int/mental_health/evidence/en/promoting_mhh.pdf, accessed 19 April 2015).

- Keleher H, Armstrong R. Evidence-based mental health promotion resource. Melbourne, Australia: Public Health Group, Victorian Government Department of Human Services; 2006 (http://www.gwhealth.asn.au/data/mental_health_resource.pdf, accessed 19 April 2015).

- World Health Organization, Department of Mental and Substance Abuse in collaboration with the Prevention Research Centre of the Universities of Nijmegen and Maastricht. Prevention of mental disorders: effective interventions and policy options. Summary report. Geneva: World Health Organization; 2004 (http://www.who.int/mental_health/evidence/en/prevention_of_mental_disorders_sr.pdf, accessed 19 April 2015).

- Prevention and promotion in mental health. Geneva: World Health Organization; 2002 (http://www.who.int/mental_health/publications/prevention_promotion_mh_2002/en/,accessed 19 April 2015).

\section{Research}

- Evidence-informed Policy Network (EVIPNet) [website]. Geneva: World Health Organization (http://global.evipnet.org/, accessed 19 April 2015).

- Mental Health Innovation Network [website].London: The Centre for Global Mental Health (http://mhinnovation.net/, accessed 19 April 2015).

- TolWA, Patel V, Tomlinson M, Baingana F, Galappatti A, Silove D, et al. Relevance or excellence? Setting research priorities for mental health and psychosocial support in humanitarian settings. Harv Rev Psychiatry. 2012 Jan-Feb;20(1):25-36. PMID: 22335180.

- Tomlinson M, Rudan I, Saxena S, Swartz L, Tsai AC, Patel V. Setting priorities for global mental health research. Bull World Health Organ. 2009 Jun;87(6):438-46. PMID: 19565122.

- Collins PY, Patel V, Joestl SS, March D, Insel TR, Daar AS, et al. Grand challenges in global mental health. Nature. 2011 July;475(7354):2730. PMID: 21734685. 